\title{
Analyzing Near-Surface Regions of Hydrophobic and Long-Term Weathered Natural Stones at Microscopic Scale
}

\author{
Franziska Braun ${ }^{1, *,+}\left(\mathbb{D}\right.$, Jeanette Orlowsky ${ }^{1,+}(\mathbb{D})$ and Stefan Brüggerhoff $2,+$ \\ 1 Department of Building Materials, Technische Universität Dortmund, August-Schmidt-Str. 8, \\ 44227 Dortmund, Germany; jeanette.orlowsky@tu-dortmund.de \\ 2 Deutsches Bergbau-Museum Bochum, Am Bergbaumuseum 28, 44791 Bochum, Germany; \\ stefan.brueggerhoff@bergbaumuseum.de \\ * Correspondence: franziska2.braun@tu-dortmund.de; Tel.: +49-231-755-4840 \\ + These authors contributed equally to this work.
}

Received: 13 May 2020; Accepted: 27 May 2020; Published: 12 June 2020

\begin{abstract}
The visual appearance of building structures is an important attribute which reflects the character and identity of a region. Due to the influence of weathering, the surfaces of building stones alter, leading to aesthetic changes of the material surface such as discoloration or darkening. In this study, near-surface regions of weathered Baumberger (BST), Schleeriether (SST), and Obernkirchener Sandstones (OKS) have been analyzed at the microscopic scale in order to investigate the intensity and the extent of visual as well as structural changes and how both can be affected due to the presence of surface treatments with hydrophobing agents. It could be detected that aesthetic changes appeared already after 2 years of outdoor exposure, with the slightest variations on BST surfaces, followed by SST and OKS. The use of hydrophobing agents leads to a reduction in surface darkening in the short term. After long-term weathering, no significant changes are visible, as similar values in total color difference $\left(\Delta \mathrm{E}^{*}\right)$ were measured. Biogenic growth and the formation of black weathering crusts are the main reasons for color alterations in the case of the examined stones. The surface damages occur especially on calcareous (BST) followed by clayey (SST) and quartzitic (OKS) stone surfaces.
\end{abstract}

Keywords: natural stone; hydrophobic agents; long-term weathering; durability; weathering damages; color alterations; structural changes

\section{Introduction}

For building stones, especially in the field of cultural heritage, continuous maintenance is required, but it often does not take place [1]. For this reason and due to the influence of weathering processes, natural stones alter to different degrees. This altering always depends on their specific petrographic and petrophysical properties, like mineral composition, type of binding, and specific pore space characteristics [2,3]. Over the course of time, this has a direct effect on the surface conditions of the weathered stones, such as the intensity of surface darkening or color changes, and also on material loss or the formation of undesirable crusts.

The visual appearance of building structures, including the color impression of the used building material, is an important attribute which reflects the character and identity of a region. Color alterations which appear over time on building stone surfaces are caused by different environmental factors, which can be summarized as biological, chemical, or physical processes. Changes in the original color can appear due to biogenic growth, salt-related damage, anthropogenic-induced pollution, the accumulation of (dark) particles, crust formation, changes in humidity, or conservation actions [1,4-7]. Discolorations, like greening or darkening, can already occur after a short weathering time [8,9]. The intensity and 
extent depend especially on the exposure direction (weather-facing side or sheltered areas), as well as on the wetting and drying behavior of the near-surface zones of the stone [9]. The longer surfaces stay wet, the higher the possibility of biogenic colonization [8]. These biofilms, including fungi, algae, cyanobacteria, heterotrophic bacteria, lichens, and mosses [5], protect surfaces from weathering or absorbing water [10]. In combination with the accumulation of particles and formation of gypsum crusts, they may also lead to aesthetic deterioration and the structural degradation of the uppermost zones $[5,11]$. This study focusses on the analysis of near-surface regions of weathered stone samples. Furthermore, it investigates the intensity and the extent of visual and structural changes and how both can be affected due to the presence of surface treatments with hydrophobing agents based on organosilicon compounds.

In this context, field exposure tests offer a suitable possibility to study the durability of different types of natural stones under the influence of different weathering conditions [12-17]. For such tests, the specimens are prepared and mounted on plates [15], stored on a rack [17], or are part of a test wall [12], and then are exposed with a specific orientation to different environmental conditions. With this experimental setup, it is possible to investigate the extent of superficial damages and changes in the rock properties over time, caused by, e.g., intensive air-pollution, the wet or dry deposition of $\mathrm{SO}_{2}$ and NOx, biogenic colonization, or climate changes. In this context, also reliable statements of the long-term efficiency of hydrophobic surface treatments can be made and information on the extent of weathering can be obtained $[17,18]$.

In this study, treated and untreated samples of different calcareous (Baumberger Sandstone), clayey (Schleeriether Sandstone), and quartzitic-bound natural stones (Obernkirchener Sandstone) have been examined after an exposure time of up to 24 years. During their time of exposure, the surfaces of the test specimens were kept unprocessed, which is why the superficial color alterations (e.g., discoloration and darkening) represent a real timescale and are worth being examined in detail. The stone specimens were exposed at different locations in Germany with varying environmental conditions [17] but in general to a Central European climate (see also [19]). The investigation of the actual condition of these long-term weathered surfaces therefore represents an important contribution to future conservation measures, especially in the field of cultural heritage.

As part of a research project funded by the German Research Foundation on the long-term behavior of hydrophobic and weathered natural stone surfaces, the first part of investigations has already been performed with non-destructive single-sided NMR (nuclear magnetic resonance) measurements. The studies discussed the effectiveness of these long-term weathered hydrophobic stone surfaces using a newly developed evaluation system $[3,20]$. Moreover, in [19] the influence of these treated and weathered stone surfaces on the water absorption behavior in conjunction with the extent of superficial damages, expressed by a calculated damaged depth, have been analyzed. The investigations presented in this paper have been carried out on the basis of the above-mentioned results using four different testing methods: (i) color measurements in the CIE $\mathrm{L}^{*} \mathrm{a}^{*} \mathrm{~b}^{*}$ color system for analyzing the intensity of visual changes over time; (ii) polarization microscopy for detailed investigations of the visual and structural alterations and changes in the surface morphology; (iii) scanning electron microscopy; and (iv) X-ray diffraction analysis for a more detailed examination of the surface-related weathering layers.

\section{Materials and Methods}

\subsection{Material}

The samples investigated in this study were obtained from a former field study, which was started by the Zollern-Institute (Deutsches Bergbau-Museum Bochum) in $1986[17,18]$ and extended to a project duration of over 30 years. Ten different types of stone were exposed at six different exposure sites in Germany. A triangle-prismatic geometry, related to the building structures on site, was specially chosen for the test specimens. Eleven samples of each type were soaked with organosilicon containing 
hydrophobing agents, and two samples remained untreated. The samples were impregnated for one minute by a complete immersion in the respective hydrophobing agent. After a curing time of three months, the stone samples were exposed to three sites in North-Rhine Westphalia (Dortmund, Duisburg, Eifel) and to three sites in Bavaria (Nuremberg, Munich, Kempten). Additionally, treated and untreated reference samples were stored in an archive over the whole project time. After an on-site exposure of 2, 17 (for some samples), 24, and, for some samples, after 30 years, thin slices (about $3 \mathrm{~cm}$ ) were cut from each specimen (Figure 1).
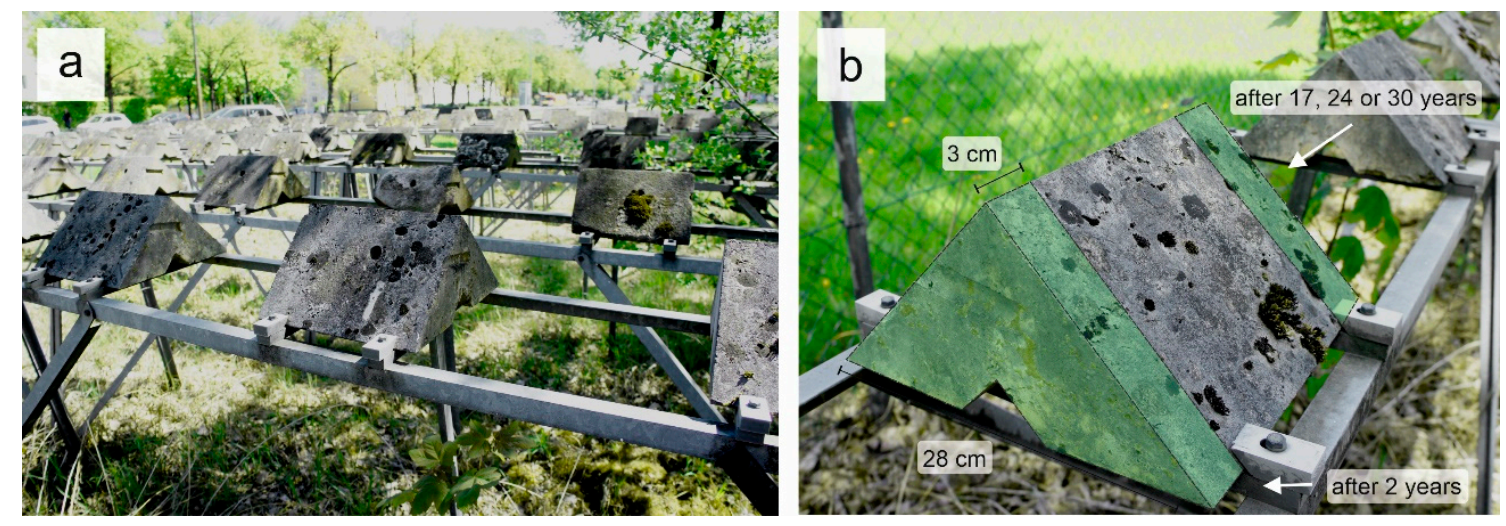

Figure 1. (a) Exposure site in Munich after 30 years of outdoor weathering. (b) Schematic illustration of sample preparation. After 2 and 17 or $24 / 30$ years, $3 \mathrm{~cm}$ thick slices have been cut out of the weathered stone prisms.

The investigations presented in this study were performed on three different types of stone: Baumberger (BST), Schleeriether (SST), and Obernkirchener Sandstone (OKS). Their mineral composition, which has been analyzed using thin sections and X-ray diffraction (see Section 2.2), as well as their petrophysical properties, are listed in Table 1. Their appearance in unweathered conditions can be found in [21].

Table 1. Mineral composition and petrophysical properties of Baumberger (BST), Schleeriether (SST), and Obernkirchener Sandstone (OKS). The petrophysical properties have been measured by mercury intrusion porosimetry according to DIN 66133 [22].

\begin{tabular}{|c|c|c|c|}
\hline Stone Type & $\begin{array}{l}\text { Baumberger Sandstone } \\
\text { (BST) }\end{array}$ & $\begin{array}{l}\text { Schleeriether Sandstone } \\
\text { (SST) }\end{array}$ & $\begin{array}{l}\text { Obernkirchener Sandstone } \\
\text { (OKS) }\end{array}$ \\
\hline color & $\begin{array}{c}\text { yellowish-grey } \\
10 \text { YR } 8 / 2-5 \text { Y } 7 / 2\end{array}$ & $\begin{array}{l}\text { light green to grey } \\
5 Y 7 / 2\end{array}$ & $\begin{array}{l}\text { beige to yellowish-grey } \\
5 \text { Y } 8 / 1-5 Y 7 / 2\end{array}$ \\
\hline mineral content & $\begin{array}{c}\text { calcite } 55 \% \\
\text { quartz } 25 \% \\
\text { clay minerals } 5 \% \\
\text { glauconite } 15 \%\end{array}$ & $\begin{array}{c}\text { quartz } 65 \% \\
\text { feldspar } 5 \% \\
\text { rock fragments } 20 \% \\
\text { muscovite } 10 \%\end{array}$ & $\begin{array}{l}\text { quartz } 85 \% \\
\text { rock fragments } 10 \% \\
\text { muscovite } 5 \%\end{array}$ \\
\hline matrix & calcareous-clayey & clayey-chloritic & quartzitic, kaolinitic \\
\hline characterization & $\begin{array}{l}\text { fine pored fine-grained sandy } \\
\text { limestone }\end{array}$ & $\begin{array}{l}\text { fine-grained, moderately sorted } \\
\text { sandstone }\end{array}$ & $\begin{array}{l}\text { fine-grained, well sorted quartzitic } \\
\text { sandstone }\end{array}$ \\
\hline classification & Wackestone & Litharenite & Quartzarenite \\
\hline weathering damages & $\begin{array}{l}\text { black gypsum crusts, scaling, } \\
\text { sanding }\end{array}$ & scaling, sanding, salt damage & black crusts, spalling \\
\hline total porosity [\%] & 20 & 19 & 20 \\
\hline bulk density $\left[\mathrm{g} / \mathrm{cm}^{3}\right]$ & 2.17 & 2.15 & 2.16 \\
\hline apparent density $\left[\mathrm{g} / \mathrm{cm}^{3}\right]$ & 2.73 & 2.64 & 2.71 \\
\hline average pore radius $[\mu \mathrm{m}]$ & 0.5 & 4.1 & 3.4 \\
\hline
\end{tabular}


All the stone types are quite prominent in Germany but also in some other regions in Europe, and several monuments comprise of ashlar. Baumberger and Obernkirchener Sandstone are quarried and commonly used in northern Germany (e.g., Cologne Cathedral) and The Netherlands (see [3,21,23]). Schleeriether Sandstone is more typically used as a building material in regions in southern Germany. The Würzburg Residence or the St. James's Church in Rothenburg ob der Tauber are partially built from it [21].

In the following, results from test specimens will be presented, which were treated with the protective agents shown in Table 2 and exposed to the exposure sites in Dortmund (DO), Duisburg (DUI), Eifel (EI), Nuremberg (NBG), Munich (MUC), Kempten (KE), and the archive (A) (for more details concerning the exposure sites, see [19]). The hydrophobic products of Table 2 are based on organosilicon compounds and can be divided into silanes, siloxanes, and silicone resins. Agents 3, 4, 5, and 10 additionally contain silicic acid ester (SAE), which acts as a coupling agent.

Table 2. Protective agents, their chemical composition, and their active ingredient content [\%] $(\mathrm{SAE}=$ silicic acid ester $)$.

\begin{tabular}{|c|c|c|}
\hline Identification Number & Protective Agent & Chemical Classification \\
\hline 1 & $34 \%$ propyl-, $5 \%$ octyltrimethoxysilane & silane \\
\hline 3 & $20 \%$ isobutyltrimethoxysilane, $20 \%$ tetraethoxysilanhydrolysat & silane + SAE \\
\hline 4 & $20 \%$ isobutyltrimethoxysilane, $20 \%$ tetraethoxysilane & silane + SAE \\
\hline 5 & $75 \%$ low-molecular methylethoxysiloxane + tetraethoxysilane & siloxane + SAE \\
\hline 8 & $5 \%$ methyl-/isooctyl silicone resin & silicone resin \\
\hline 9 & $6.7 \%$ oligomeric methyl-/isooctylmethoxysiloxane & siloxane \\
\hline 10 & $8.3 \%$ oligomeric methyl-/isooctylmethoxysiloxane + tetraethoxysilane & siloxane + SAE \\
\hline 11 & $8 \%$ polymeric methylmethoxysiloxane & silicone resin \\
\hline
\end{tabular}

\subsection{Investigations}

\subsubsection{Color Measurements in the CIE System}

Colorimetric measurements enable to investigate alterations in the visual appearance of stone surfaces caused either by the initial conservation action or by the influence of long-term weathering for more than 24 years. A spectrophotometer spectro-guide sphere gloss from BYK-Gardner has been applied according to DIN EN 16581 [24] and DIN EN 15886 [25] (for more details, see [19]).

For these measurements, the samples were prepared by cutting the test specimens to obtain a weathered-treated surface (representing the current status of the specimen surfaces) and an unweathered-untreated back side ( $\hat{=}$ reference). Five measuring points were recorded each, with a total of 4690 measuring points. The results were presented in the CIE L*a* $\mathrm{b}^{*}$ color system, where color is expressed with the following parameters: $L^{*}$ is the lightness ranging from black $(=0)$ to white $(=100), a^{*}$ is the red-green coordinate $\left(a^{*}=\right.$ red; $-a^{*}=$ green $)$, and $b^{*}$ is the yellow-blue coordinate $\left(b^{*}=\right.$ yellow; $b^{*}=$ blue $)$ in a Cartesian coordinate system.

The applied hydrophobic agents are not expected to considerably influence the appearance of the stone surfaces and should not lead to a darkening of the surface after the initial treating procedure. In order to determine the extent of color alterations of the long-term weathered stone surfaces, the total color difference $\left(\Delta \mathrm{E}^{*}\right)$ has been calculated from the values of $\Delta \mathrm{L}^{*}, \Delta \mathrm{a}^{*}$, and $\Delta \mathrm{b}^{*}$ according to:

$$
\Delta E^{*}=\sqrt{\left(\Delta L^{*}\right)^{2}+\left(\Delta a^{*}\right)^{2}+\left(\Delta b^{*}\right)^{2}}
$$

A $\Delta \mathrm{E}^{*}>5$ is rated as a different color [26,27]. In this paper, this represents the limit value of noticeable changes (marked in the diagrams as dashed lines). 


\subsubsection{Microscopic Examinations and X-ray Diffraction Measurements}

The mineral composition, type of binding, and internal structure of the stone samples have been characterized using polarization microscopy, X-ray diffraction, and scanning electron microscopy (SEM) (see Table 1). A total of 49 uncovered thin sections impregnated with blue-dyed resin have been analyzed with a Zeiss Axio Imager.M2 microscope in order to investigate the mineral composition, internal structure, and changes in the near-surface regions. By analyzing this uppermost zone of the weathered and treated samples at the microscopic scale, more detailed information about the influence of long-term weathering as well as of the initial hydrophobic treatment is possible. Moreover, the extent of the structural and visual superficial changes can be assessed-e.g., the impact of biogenic weathering can be examined in detail on and below the surface.

SEM measurements with a TESCAN MIRA3 were carried out on 11 selected samples in order to analyze the stone composition, stone fabric, and changes in morphology in more detail. All the samples were sputtered with carbon (C) and examined in SE mode (secondary electrons).

The composition of the uppermost zone and specifically the presence of damaging salts, which can lead to structural and visual changes, was analyzed on a selection of samples by X-ray diffraction (XRD) using a Philips PW 1830/3020 and the analyzing software Panalytical X'pert Plus.

Using these four different measuring techniques, the interaction between substrate, different weathering patterns, and the passage of time, as well as the intensity of the resulting damage potential and the extent of structural and visual changes, can be analyzed.

\section{Results and Discussion}

\subsection{Color Changes}

Concerning alterations in the visual appearance of the stone surfaces (Figure 2), the most significant changes were detected between the unweathered (A) and 2-year-weathered samples (Figure 3). This occurs extremely on the untreated OKS sample exposed in Dortmund, which shows a $\Delta \mathrm{E}^{*}$ value of 34 . After 2 years of weathering, the average $\Delta \mathrm{E}^{*}$ value of untreated BST surfaces is about $8( \pm 3)$. These nearly constant values imply a similar weathering rate in the first 2 years of exposure as well as a comparable visual appearance of the untreated stone surfaces on the different exposure sites. After 24 years of exposure, a constant increase in $\Delta \mathrm{E}^{*}$ can be seen for these samples, with $\Delta \mathrm{E}^{*}$ values of about 17 $( \pm 2)$. Macroscopically, the 24-years-weathered BST surfaces show an extensive darkening (untreated and treated, Figure 2). In contrast, independent of the time of outdoor exposure, untreated weathered SST samples reach nearly similar $\Delta \mathrm{E}^{*}$ values, with a total color difference of $18( \pm 5)$ after 2 years and $18( \pm 2)$ after an exposition time of over 24 years.

Regarding the surfaces treated with a siloxane-based water repellent (agent 5), the results of the $\Delta \mathrm{E}^{*}$ for BST are similar to the untreated samples (Figure 3). Slight differences occur for samples after 2 years of exposure with lower $\Delta \mathrm{E}^{*}$ values of about $5( \pm 2)$. These results indicate an effective self-cleaning effect, causing a lower degree of dust or particle accumulation on the treated BST surfaces. Compared to the untreated samples, the siloxane-treated surfaces of SST and OKS also lead to a reduction in $\Delta \mathrm{E}^{*}$ values, which can be especially seen in the first 2 years of outdoor weathering. For OKS samples exposed to the locations in Bavaria and the Eifel, the self-cleaning effect is more pronounced than for the exposure sites in Dortmund and Duisburg. However, this effect ceases after a long-term weathering of 24 (EI) and 30 years (for the Bavarian exposure sites NBG, MUC, and KE). This is contrasted by the total color differences in the long-term weathered treated SST samples, where the $\Delta \mathrm{E}^{*}$ stays nearly at the same level of $12( \pm 3)$. 

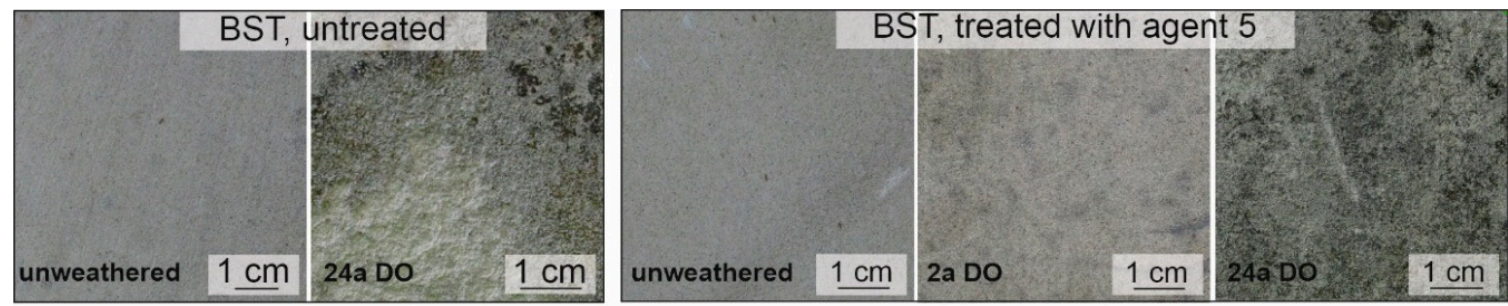

Figure 2. Top views of untreated (left) and treated (agent 5) BST samples (right), unweathered and weathered for 2 years and 24 years at the exposure site Dortmund.
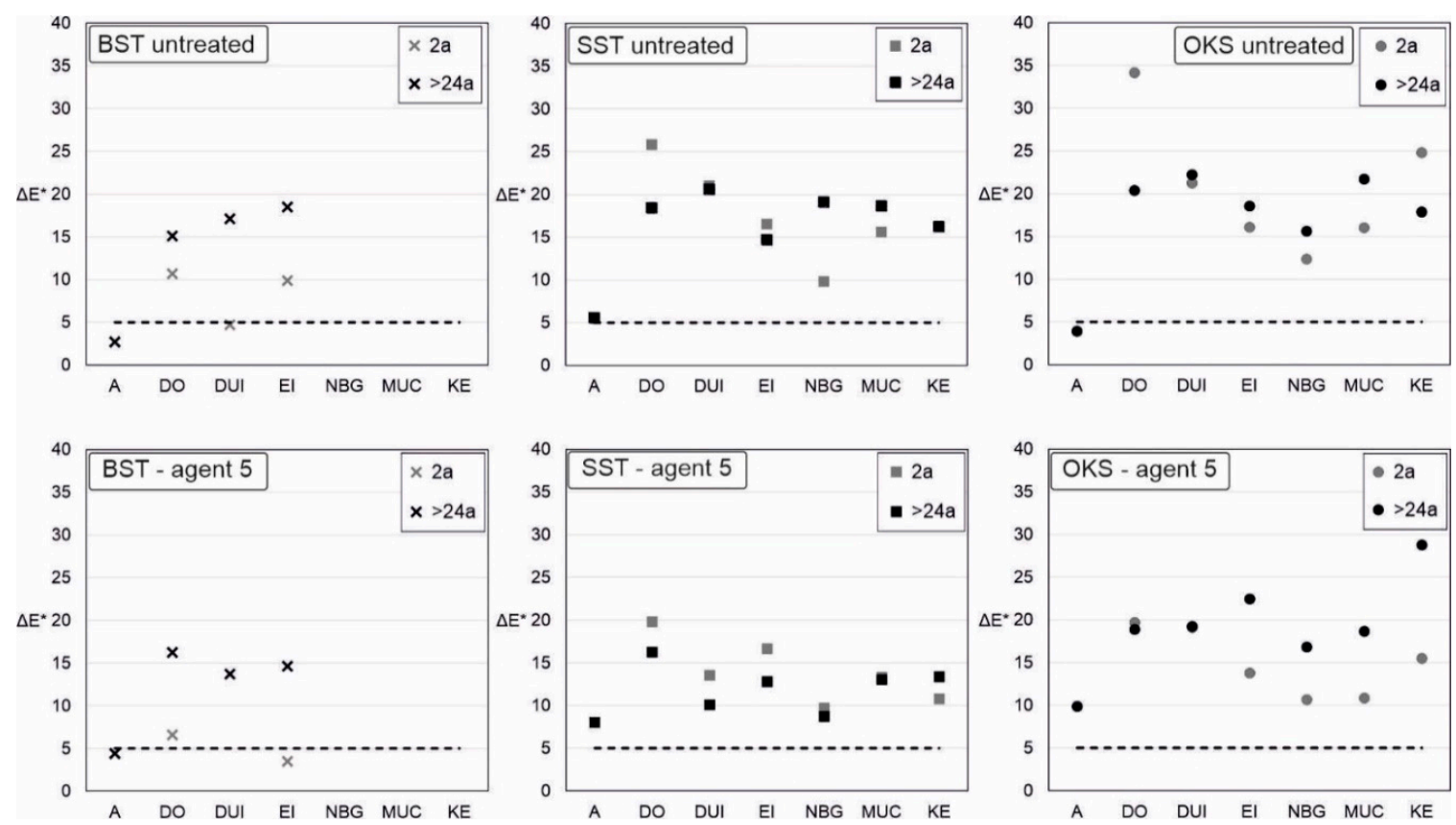

Figure 3. Total color difference $\left(\Delta \mathrm{E}^{*}\right)$ of untreated and siloxane-treated (agent 5) BST, SST, and OKS samples exposed for 2, 24, or 30 years at the locations in North-Rhine Westphalia (Dortmund (DO), Duisburg (DUI), Eifel (EI)) and Bavaria (Nuremburg (NBG), Munich (MUC), Kempten (KE)). As unweathered references, samples from the archive (A) were taken.

All the measured $\Delta \mathrm{E}^{*}$ values (except the short-time weathered BST samples and samples from the archive) are unambiguously higher than the limit value $\left(\Delta \mathrm{E}^{*}>5\right)$. Thus, it can be stated that a slight reduction in surface darkening is possible due to the application of hydrophobic agents. Nevertheless, significant changes in appearance will occur due to natural weathering, whether treated or not treated.

To compare the overall changes in the color of untreated and treated stone surfaces, the $\Delta \mathrm{E}^{*}$ values have been averaged over all the exposure sites for all the exposed samples. In Figure 4, the different hydrophobic agents (1-11) applied on BST, SST, or OKS and the total differences in color after 2 and more than 24 years are presented. 


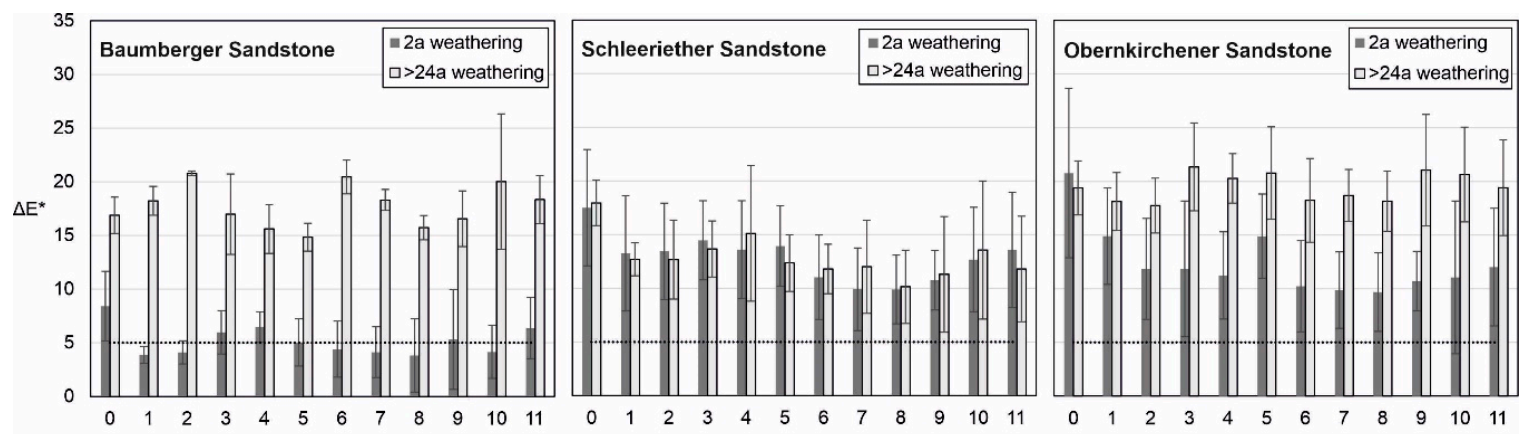

Figure 4. Total color difference $\Delta \mathrm{E}^{*}$ of untreated (0) and treated (1-11) BST, SST, and OKS samples (mean value and standard deviation averaged over all the exposure sites).

For the untreated BST samples, the $\Delta \mathrm{E}^{*}$ values after 2 years of weathering are almost twice as high as for surfaces impregnated with the analyzed hydrophobic agents (see also Figure 3). Independent of the type of water repellent, the total color difference after 2 years of outdoor exposure is between 5 and a maximum of 10 (for agent 9). Due to the long-term weathering, the $\Delta \mathrm{E}^{*}$ is about double for all the treated and untreated BST samples (Figure 4). A high scattering width could be detected for the BST samples treated with agent 10, indicating varying weathering rates of these treated surfaces at the different exposure sites. In contrast, the SST samples show a significant increase in $\Delta \mathrm{E}^{*}$ already after 2 years of outdoor exposure, with values starting at 10 and reaching a maximum of 23 (for untreated SST). These color alterations do not change noticeably over 24 years of exposure, implying that the initial darkening of the surface stays at a same constant level.

Figure 4 also indicates that impregnated surfaces of 2-year-exposed OKS samples in general show lower $\Delta \mathrm{E}^{*}$ values (between 10 and 15) compared to untreated ones $(21( \pm 8)$ ), regardless of the type of hydrophobic agent. After a weathering period of more than 24 years, the differences between the untreated and treated surfaces nearly disappeared. The values of the total color difference are around 20 , which implies in the longer term an equally pronounced weathering and darkening rate for treated and untreated OKS surfaces.

These significant changes in the original color of the investigated stone surfaces obviously occurred over time due to the influence of various environmental factors (also refer to [6]). Since visual and structural changes develop in the uppermost zone of the naturally weathered samples, thin sections have been examined at a microscopic level. In addition, changes from the stone surface to deeper areas of the stone were investigated in detail.

\subsection{Microscopic Examinations and X-Ray Diffraction Measurements}

Figure 5 presents different types of lichens growing on the surfaces of 24-years-weathered treated (Figure 5a,b) and untreated (Figure 5c) BST samples. Independent of the initial surface treatment, organisms colonize the stone substrate extensively, leading to a reduction in the accessible open pore space, which can in general influence the water absorption behavior via the stone surface over time $[10,28]$. Biogenic growth on BST surfaces is detected with a size of a few $100 \mu \mathrm{m}$ in height and width and a length of up to more than $600 \mu \mathrm{m}$. Due to swelling and shrinkage processes of the surface-covering biofilms, a noticeable disaggregation of the fabric may take place. Over time, this can result in a loss of cohesion as well as a loss of material in this uppermost zone (see Figure $5 c$, also refer to [5]). 

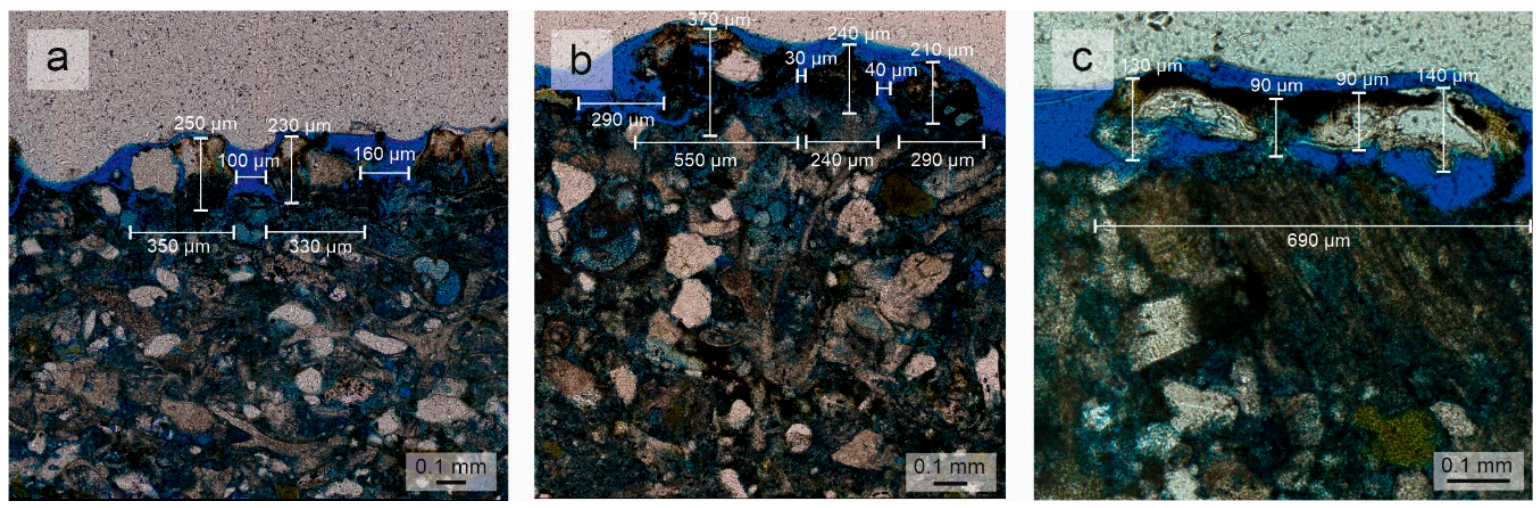

Figure 5. Treated BST (agent 8 (a); agent $5(\mathbf{b}))$ and untreated BST (c), weathered for 24 years at EI (a) and DUI $(\mathbf{b}, \mathbf{c})$. Different biogenic growth types (lichens) can be seen in plane polarized light.

These biofilms settle with a superficial attachment on the stone substrate, but they can also extend roots inside the stone matrix (Figure 6). The fungal hyphae penetrate the calcareous substrate of BST, causing dissolution in the direct adjacent areas. This deterioration of the stone fabric by fungi was also described by [5,7]. The created network builds up a secondary porosity with a pore diameter of between 4 and $8 \mu \mathrm{m}$, and it may provide new pathways for water transport processes.
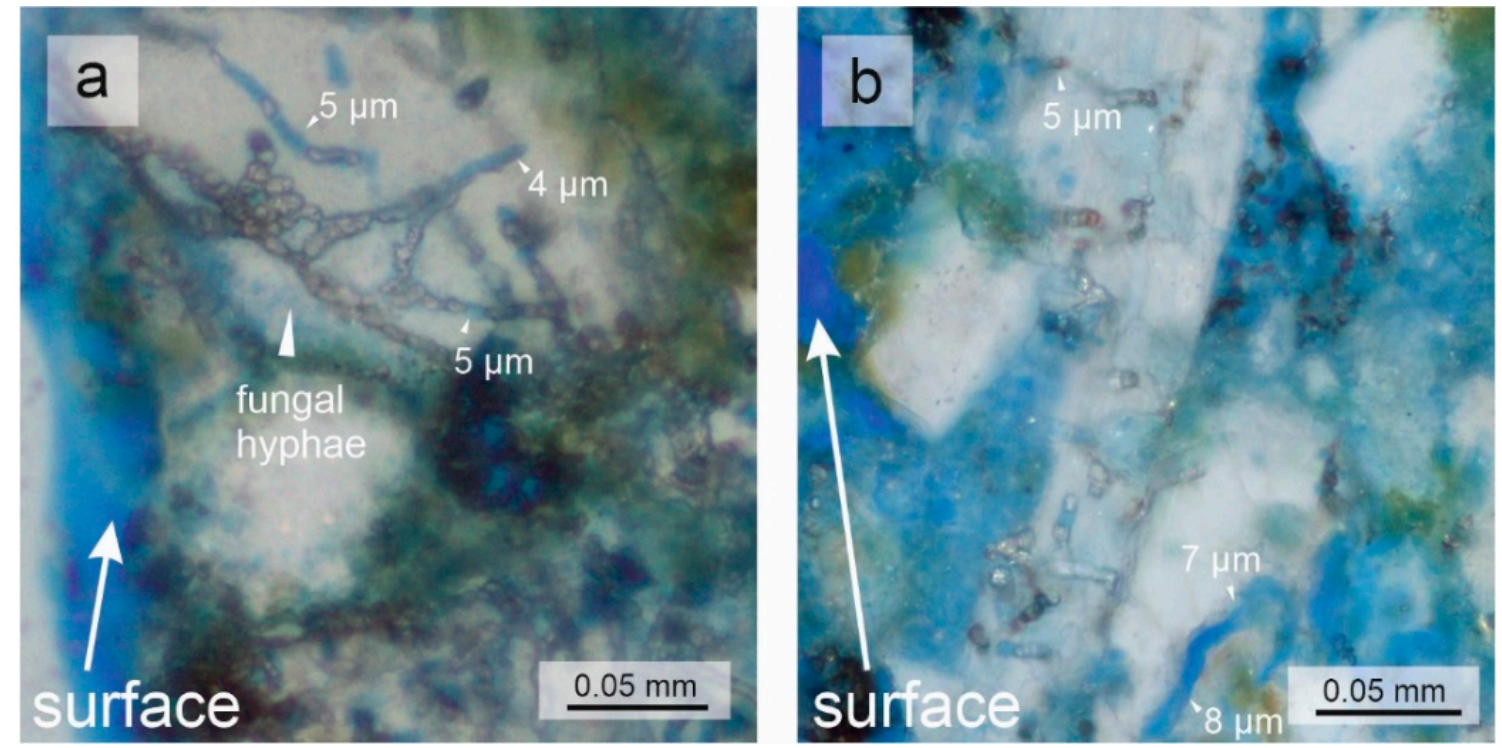

Figure 6. Root penetration in calcareous components of BST samples, treated with agent 5 (a) and agent 6 (b) and exposed to Dortmund for 24 years, incident light.

Besides the biological growth on the surface and in deeper areas of the calcareous BST, the formation of black crusts has also been observed on the long-term weathered untreated and treated samples. In Figure 7, the XRD results show the presence of gypsum $\left(\mathrm{CaSO}_{4} \cdot 2 \mathrm{H}_{2} \mathrm{O}\right)$. 


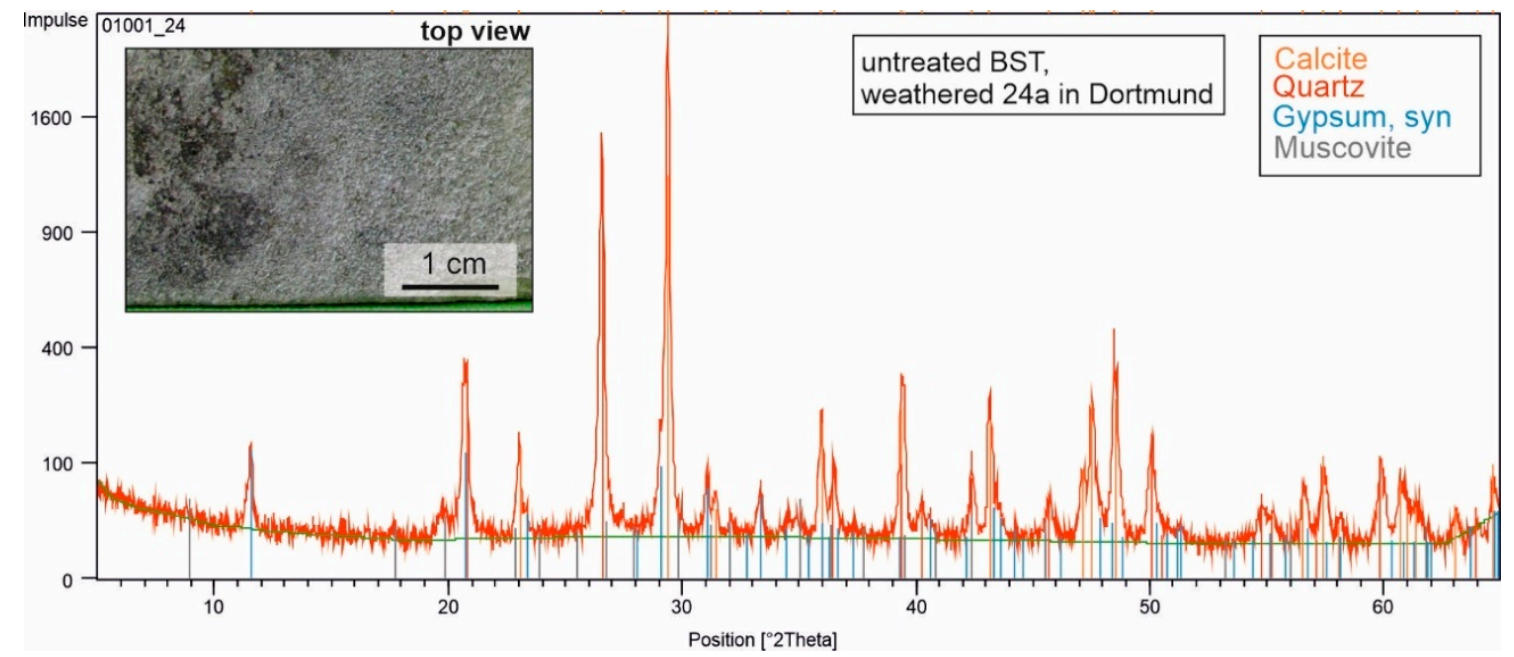

Figure 7. Results of the XRD analysis of the untreated and 24-years-weathered BST sample at the exposure site Dortmund. Detected gypsum in combination with dust particles leads to black weathering crusts on BST surfaces.

Scaling of the dark surfaces of the BST was also observed on long-term weathered samples (see also [3]). Using thin sections, the extent and depth of this weathering form was measured in detail. Figure 8 shows the long-term weathered surface of treated (agent 6) BST. In the right part, the substrate is nearly scaled off, with a loss of material of about $2 \mathrm{~mm}$. In the remaining intact part, the formation of several surface parallel cracks is observed. They vary between 2 and $4 \mathrm{~mm}$ in length and 0.4 and $1.7 \mathrm{~mm}$ in depth.

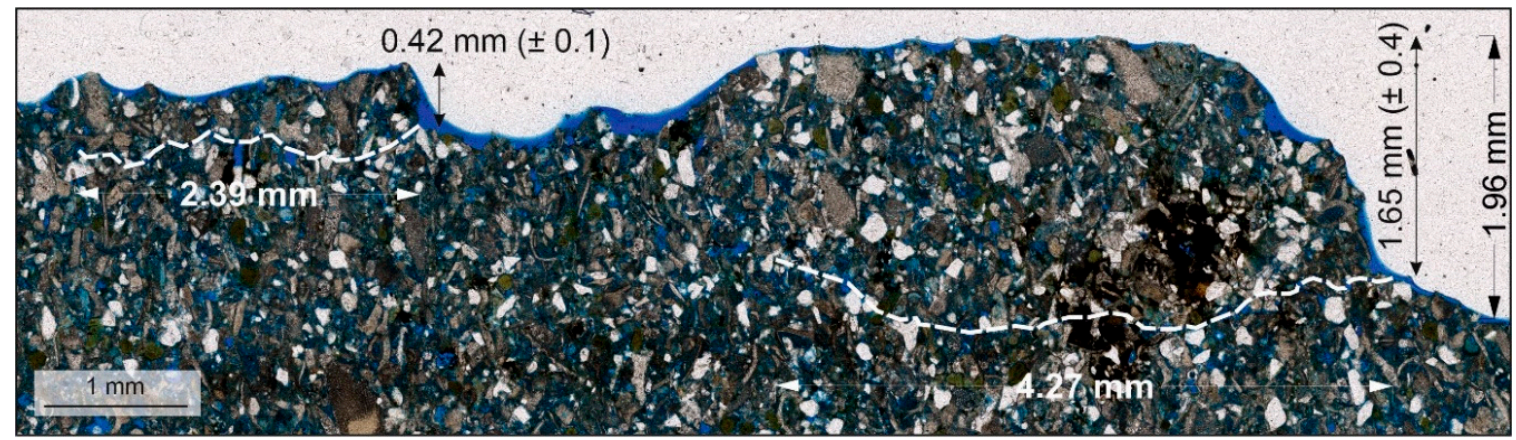

Figure 8. Formation of scaling and cracks on the BST surface treated with agent 6 and weathered for 24 years in Dortmund, in plane polarized light. The depth extent of the cracks (mm) was measured out of 10 measuring points.

On the contrary, regarding the surfaces of long-term weathered SST, only flat developed biofilms (Figure 9a,b) could be detected by a thin section analysis. Additionally, black deposits cover the SST surfaces as thin layers, with a maximum height of about 20-30 $\mu \mathrm{m}$ (Figure 9c). Compared to BST, less activity of biofilms and the rooting of fungal hyphae were found in the uppermost zone of the SST samples. 

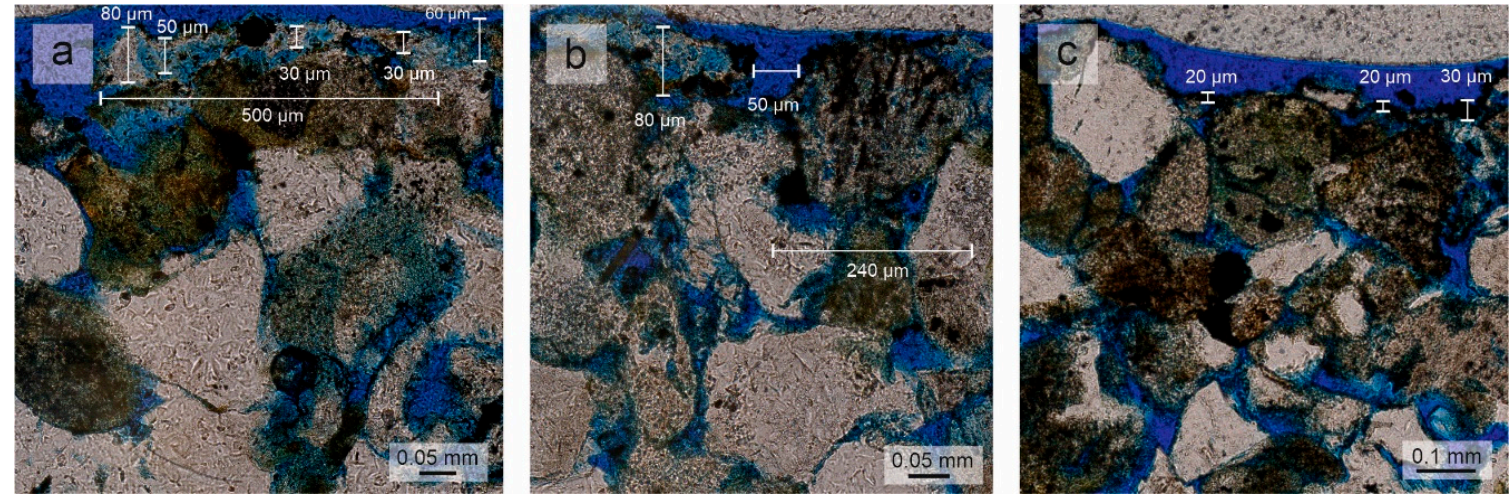

Figure 9. SST sample treated with a siloxane (agent 7) and exposed in Duisburg for 24 years. Thin biogenic growth appears in combination with black deposits $(\mathbf{a}, \mathbf{b})$. The black crust has a height of about 20-30 $\mu \mathrm{m}(\mathbf{c})$, in plane polarized light.

Further XRD measurements have been carried out in order to retrieve information on the exact composition of the weathering layer in the superficial zone of the SST. As exemplarily demonstrated in Figure 10, besides microorganisms and deposited dark particles (Figure 9), the weathering layer consists primarily of gypsum (sulphates) as well as nitrates. The presence of further sulphates such as burkeite, arcanite, bloedite, and bassanite, which could be determined in some specimens, complete the main composition. Subordinated carbonates, e.g., nesquehonite and kalicinite, have also been detected.

Using polarization microscopy, two main covering forms can be observed in the uppermost part of OKS surfaces. The long-term weathered OKS samples show an extensive growth of lichens (around $500 \mu \mathrm{m}$ in height), which are firmly fixed to the underlying quartzitic substrate (Figure 11a). These biofilms also form part of the black weathering layers (Figure 11c). The microorganisms colonize mostly on top of the quartz grains and penetrate only occasionally into the kaolinitic pore space fillings. Near-surface pores are also filled by black deposits and microorganisms or their residuals (Figure 11b). Dense, surface covering black weathering crusts up to $50 \mu \mathrm{m}$ thickness can be detected on the OKS samples even after short-term weathering. A possible sealing of the uppermost zone caused by the crusts has been described already by [23]. Regarding the composition of the black layers of OKS, a XRD analysis did not show any evidence for the presence of gypsum or other damaging salts as constituents.

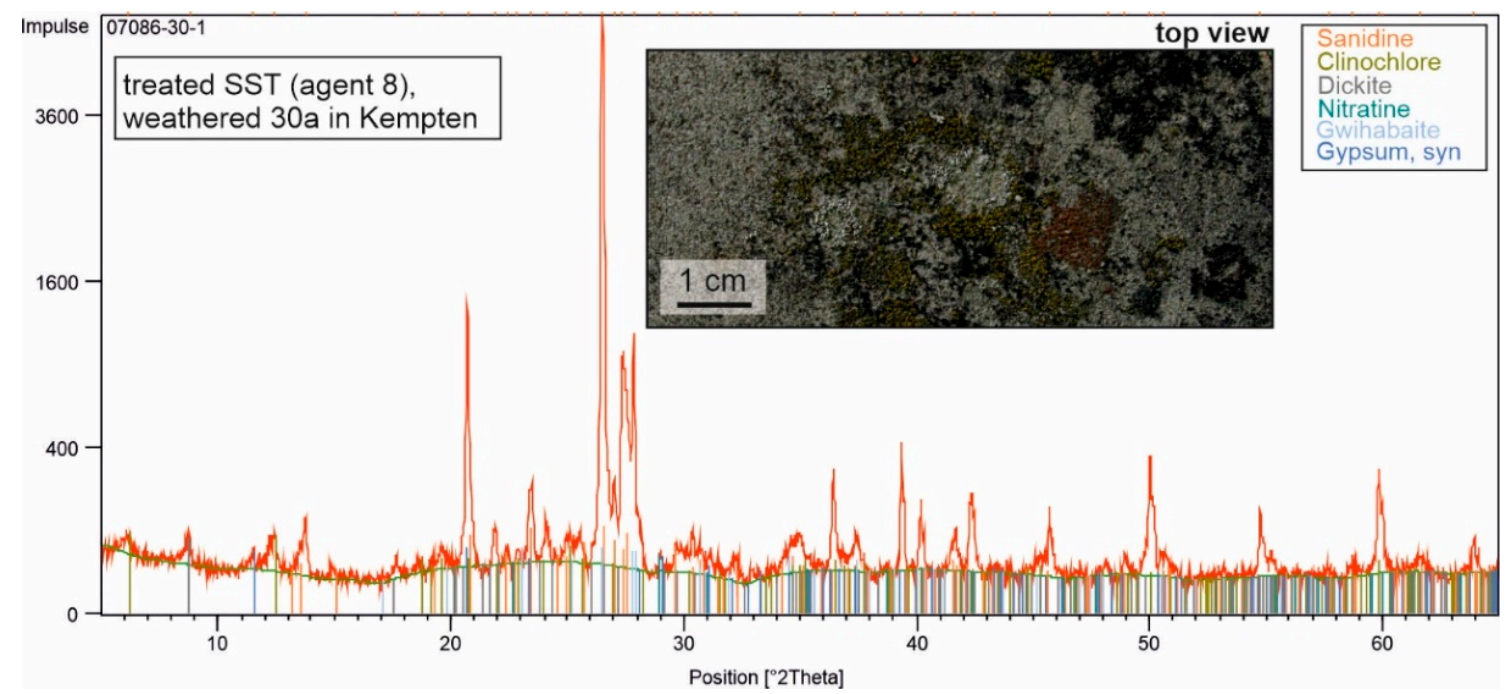

Figure 10. Results of the XRD analysis of the treated (agent 8) and 30-years-weathered SST sample at the exposure site Kempten. The examined SST weathering layer consists of gypsum $\left(\mathrm{CaSO}_{4} \cdot 2 \mathrm{H}_{2} \mathrm{O}\right)$, nitratine $\left(\mathrm{NaNO}_{3}\right)$, and gwihabaite $\left(\left(\mathrm{NH}_{4}, \mathrm{~K}\right)\left(\mathrm{NO}_{3}\right)\right)$. 

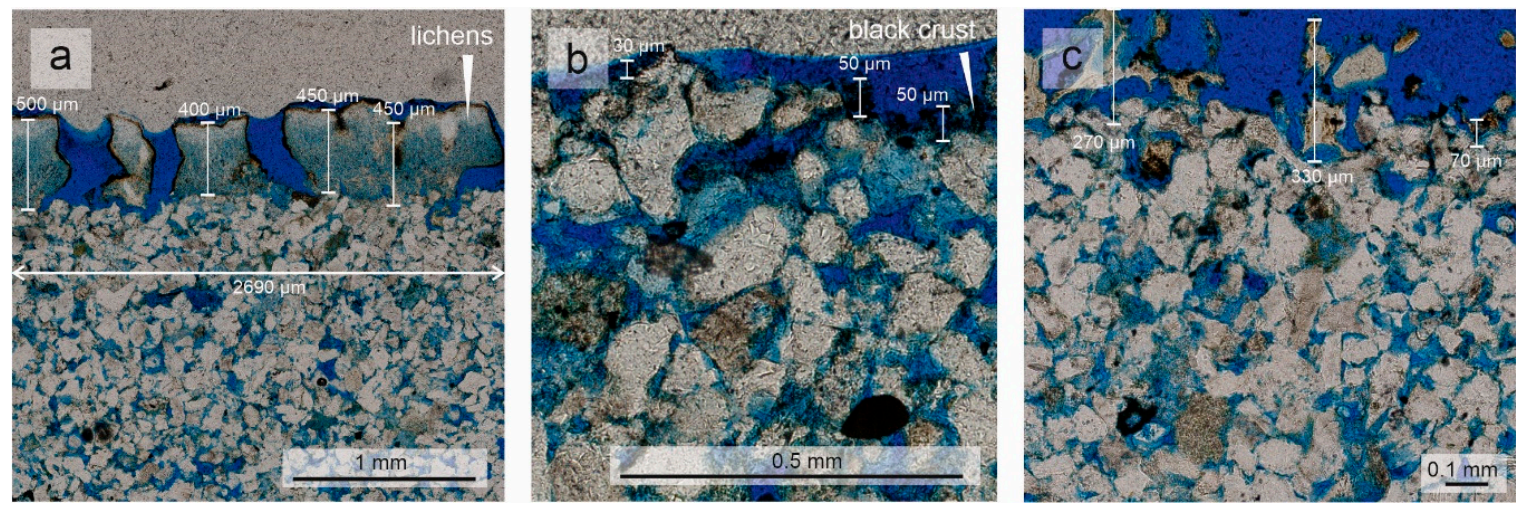

Figure 11. OKS with different weathering layers and biogenic growth forms on the surfaces of untreated and 30-years-weathered samples, exposed in Kempten (a), 2 years in Dortmund (b) and treated with agent 5 and exposed for 24 years in Dortmund (c), in plane polarized light.

The following can be noted as a summary for the treated and weathered samples: black crusts and biogenic growth had developed on all the examined and particularly on the long-term weathered surfaces. It was also observed that the microorganisms not only colonized superficially but also penetrated deeper parts of the stones, especially in case of BST. The investigated SST and OKS showed less activity of deep biological colonization. Therefore, the root penetration into the matrix of the BST samples needed to be examined more closely. Table 3 presents the results of differently treated and 24 years weathered BST samples with different penetration depths of fungal hyphae. Figure 12 exemplarily shows the measuring procedure. On the basis of thin section images in plane polarized light of the investigated samples, the depth of root penetration was determined out of 28 measuring points in a vector-based graphics program. This was done by measuring from the stones surface to the final root penetration depth in each case. These values are compared with the manually measured visible penetration depth of the applied hydrophobic agents (for the measuring procedure, see [3]).

Table 3. Biogenic rooting $[\mathrm{mm}]$ measured on different treated BST stone samples (mean value out of 28 measuring points). Penetration depth [mm] of the applied water repellents (mean value out of six measuring points).

\begin{tabular}{ccc}
\hline Sample & Biogenic Rooting & Penetration Depth Hydrophobing Agent \\
\cline { 2 - 3 } & Mean Value $[\mathrm{mm}]$ & Mean Value $[\mathrm{mm}]$ \\
\hline Agent 5-24a DO & $1.3( \pm 0.2)$ & $2.4( \pm 0.2)$ \\
Agent 6-24a DO & $1.2( \pm 0.2)$ & $2.0( \pm 0.2)$ \\
Agent 9-24a DO & $1.2( \pm 0.4)$ & $1.1( \pm 0.6)$ \\
Agent 5-24a DUI & $1.4( \pm 0.2)$ & $2.6( \pm 0.2)$ \\
Agent 6-24a EI & $0.6( \pm 0.2)$ & $1.0( \pm 0.1)$ \\
Agent 8-24a EI & $1.2( \pm 0.2)$ & $0.7( \pm 0.1)$ \\
\hline
\end{tabular}




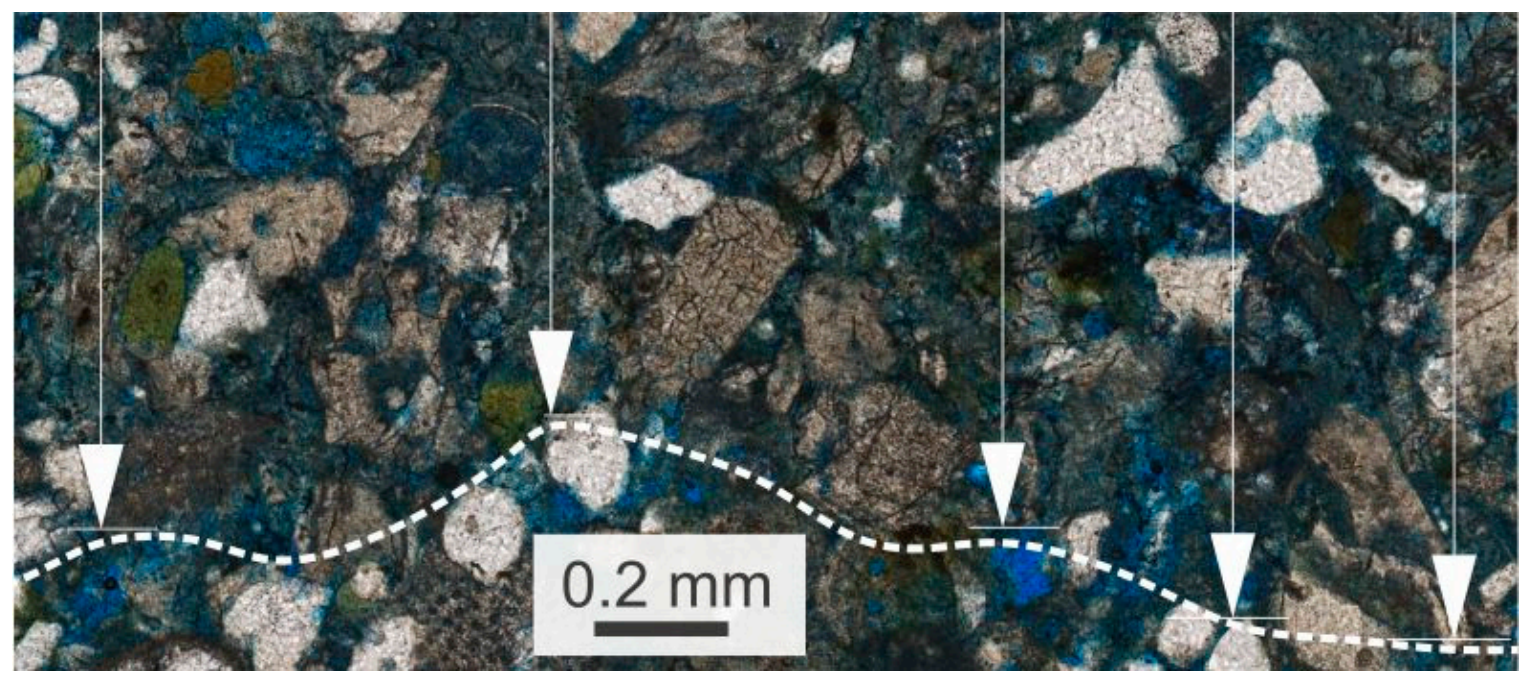

Figure 12. Picture section of the procedure for determining the depth of rooting in the matrix of a siloxane-treated BST sample (agent 5) exposed for 24 years at the exposition site Dortmund.

For all the examined samples, it can be seen that the hyphae penetrate within the hydrophobic layer and in some cases even deeper than the water repellent zone is pronounced. For samples treated with agents 5 and 6 , the penetration depth of the hydrophobic agents is nearly twice as high as the biogenic rooting. In the case of a silicone resin (agent 8), the hyphae penetrate about $0.5 \mathrm{~mm}$ deeper than the hydrophobic layer is developed. Impregnated with agent 9, the depth of rooting is equal to the penetration depth of the water repellent. Thus, it can be stated that in each case water repellent treatments did not stop the biogenic depth growth totally, and compared to the results of a thin section analysis they do not prevent a disaggregation of the fabric (Figure 6). Nevertheless, dependent on the type of protective agent, a distinction can be drawn between half rooting (agents 5, 6), complete rooting of the hydrophobic zone (agent 8 ) and rooting with almost equal penetration depth (agent 9). Regarding the long-term performance of hydrophobic surface treatments, biogenic weathering can not only affect the water repellence of just the surface, but also by rooting in deeper areas of the stone, leading to a successive disaggregation of the fabric, with a resulting decrease in hydrophobicity also in that zone.

Using SEM images, the surfaces of the weathered treated and untreated stone samples can be analyzed with a more precise surface resolution. It could be observed that surfaces of BST (Figure 13a,b) are not only covered by dense colonizing microorganisms (e.g., lichens) but are also significantly affected by their activity. In Figure 13b, intensive biogenic rooting within the calcareous and clayey porous structure can be seen, with a firm attachment of the hyphae to the matrix. The calcareous substrate is disaggregated, showing pitting, microcracks and loss of material, leading to clear structural defects in the superficial zone and to an increase in surface roughness (Figure 13a). 

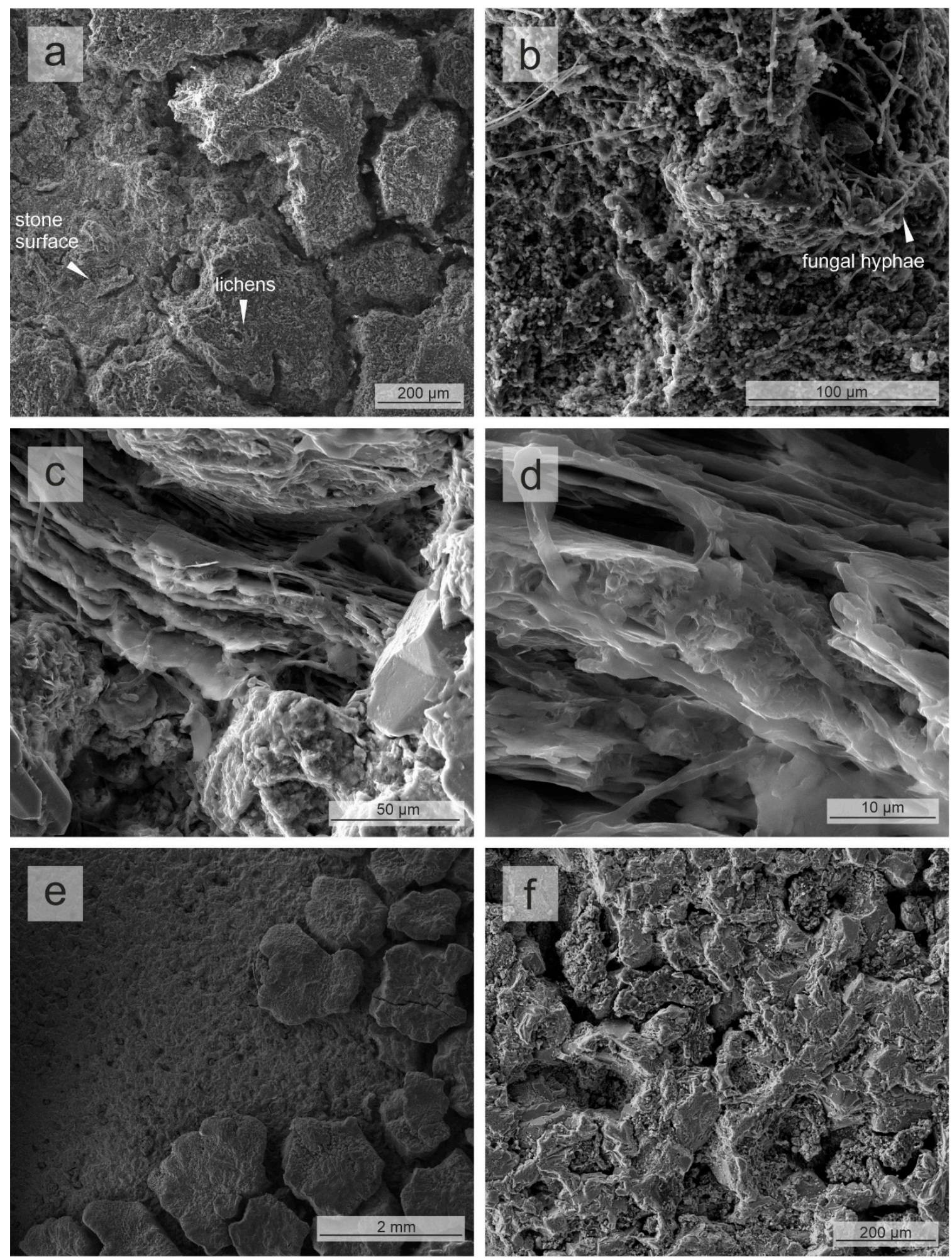

Figure 13. (a) Biogenic growth and disaggregation of the surface of untreated BST, exposed 24a in DUI. (b) Root penetration in the porous structure of treated (agent 3) BST, exposed 24a in DUI. (c) and (d) penetration of fungal hyphae in clay minerals of treated SST (agent 7), exposed 24a in DUI. (e) Microorganisms colonize surface of untreated OKS, exposed 30a in KE, causing pitting. (f) Organisms settle on the surface of treated (agent 5) OKS, exposed 24a in DO, causing pitting.

In the case of SST, the microorganisms only colonize the uppermost zone of the substrate (Figure 9), leading to root penetration and dissolution, especially of clay minerals, in this area 
(Figure 13c,d). On OKS surfaces (Figure 13e,f), an extensive biogenic colonization can be determined (Figure 11), with surface impairments such as pitting and a reduction in the kaolinitic pore space fillings. Nevertheless, it must be stated that, depending on the petrographic and petrophysical properties (see Table 1), the quarzitic matrix of OKS, with firm grain-to-grain and sutured contacts of its quartz grains, is overall not as deeply affected as the calcareous-bound BST, which finally leads to different degrees of weathering damage.

Dark weathering layers, which are close to the stone surfaces but also fill near-surface pore systems (exemplarily shown in Figure 14), mainly consist of organic structures (microorganisms), which accumulate airborne particles and also stone fragments with a firm attachment to the underlying substrate. In case of BST and SST, damaging salts, especially gypsum (Figures 7 and 10), are also constituents of these black weathering layers.
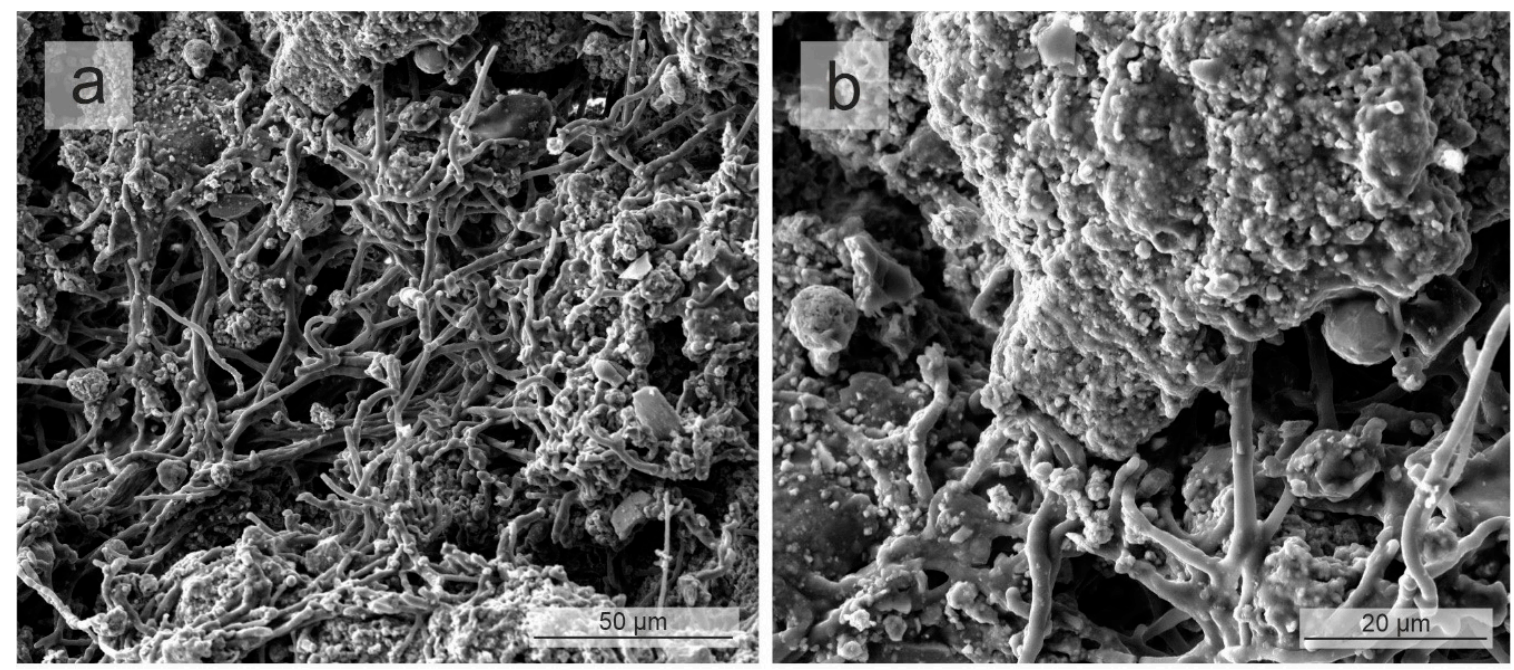

Figure 14. (a,b) Airborne particles fixed to the organic structure on the surface of treated (agent 5) BST, exposed 24a in DUI.

\section{Conclusions}

In this paper, the impact of weathering and treatment actions under the influence of time and the resulting alterations in visual appearance and structural changes have been investigated. Concerning the alterations in visual appearance measured by colorimetry, it can be stated that the most significant changes appear already after 2 years of outdoor exposure. The smallest variations are observed on BST surfaces, followed by SST and OKS. The use of hydrophobic agents leads to a reduction in surface darkening in the short term. After a long-term weathering, differences between the type of protective agent and the type of natural stone are mostly insignificant, as quite similar values in total color difference $\left(\Delta \mathrm{E}^{*}\right)$ had been obtained. In addition, no noticeable differences between 24 years (DO, DUI, EI) and 30 years (NBG, MUC, KE) of outdoor weathering exist on the different exposition sites (Figure 3).

Using thin section SEM and XRD analyses, the uppermost zone of the weathered stones can be examined with regard to the intensity of the structural changes and the presence of different weathering forms. In the case of BST, the extensive biogenic colonization of the near-surface regions in combination with black gypsum crusts is the primary reason for visual alterations. SST samples exhibit less activity of microorganisms but a higher presence of black thin and covering weathering layers on the surface. These black crusts also consist of gypsum, and further additional types of damaging salts, mainly sulphates and nitrates. Besides this, also the presence of carbonates has been measured. In the case of OKS samples, biogenic growth is strongly pronounced (growth in height), but the presence of black weathering layers (dark particles) covering the quarzitic substrate and near-surface pore systems is more severe. 
The organisms not only form biofilms, which extensively cover the surface of the weathered stones, but also root into the substrate of the stones. Concerning the root penetration in calcareous substrates, it could be detected on BST samples that over a long-term weathering of 24 years, all the applied hydrophobic agents do not hinder the depth growth of organisms into the matrix of BST. This deep rooting will complicate the cleaning of the surface.

It can be concluded that the biogenic colonization has a direct and an indirect impact on the effectiveness of the hydrophobic surface treatment. On the one hand, the biogenic rooting leads to a loosening of the uppermost zone in a mechanical (root pressure) and chemical way (dissolution of calcareous substrate). On the other hand, the hyphae as well as the additionally created pathways (secondary porosity) can transport water into deeper stone depths. For calcareous-bound stones like BST, the biogenic impact leads to a disaggregation of the stone fabric of treated and untreated samples and thus increases the ability of absorbing water. Due to the different material characteristics, a dense surface covering weathering layer is more typical for SST and OKS, which leads to a reduction in water absorption over the long term. The first results of further investigations concerning water absorption behavior have shown that capillary water transport is more reduced in weathered and untreated OKS than on SST and BST surfaces.

To sum up, biogenic growth and the formation of black weathering crusts are the main reasons for color alterations in the case of the examined calcareous (BST), clayey (SST), and quartzitic (OKS) natural stones. In general, the damages on the surfaces are the most pronounced with BST, with an intensive increase in surface roughness and the disaggregation of the calcareous fabric, followed by SST (disaggregation of clay minerals) and OKS (disaggregation of the uppermost part by pitting and reduction in superficially accessible kaolinitic pore space fillings).

Author Contributions: Conceptualization, F.B., J.O., and S.B.; methodology, J.O. and F.B.; validation, J.O., F.B., and S.B.; investigation, F.B.; writing-original draft preparation, F.B.; writing-review and editing, J.O. and S.B.; visualization, F.B.; supervision, J.O.; project administration, J.O.; funding acquisition, J.O. All the authors have read and agreed to the published version of the manuscript. All authors have read and agreed to the published version of the manuscript.

Funding: This work was performed as part of a project funded by the Deutsche Forschungsgemeinschaft (DFG, German Research Foundation), project number 342881843.

Acknowledgments: We would like to thank the Zollern-Institute, Deutsches Bergbau-Museum Bochum, who initiated in 1986 this project within the framework of the BMFT-research project "deterioration of stone-conservation of stone" for providing the stone samples for our investigations. We thank Kukui and Götte of the Department of Materials Test Engineering (WPT), TU Dortmund University, for carrying out the SEM-imaging. The authors also want to thank Jun.-nat. Panagiotis Spyridis for his comments and critical review, which greatly improved the manuscript. We acknowledge financial support by the Deutsche Forschungsgemeinschaft and Technische Universität Dortmund/TU Dortmund Technical University within the funding programme Open Access Publishing.

Conflicts of Interest: The authors declare no conflict of interest. The funders had no role in the design of the study; in the collection, analysis, or interpretation of data; in the writing of the manuscript; or in the decision to publish the results.

\section{References}

1. Garcia Pascua, N.N.; Sánchez De Rojas, M.I.I.; Frias, M. The Important Role of Colour Measurement in Restoration Works. Use of Consolidants and Water Repellents in Sandstone. In Proceedings of the 8th International Congress on Deterioration of Stone, In Proceedings of the 8th International Congress on Deterioration and Conservation of Stone, Berlin, Germany, 30 September-4 October 1996.

2. Gibeaux, S.; Thomachot-Schneider, C.; Eyssautier-Chuine, S.; Marin, B.; Vazquez, P. Simulation of acid weathering on natural and artificial building stones according to the current atmospheric SO2/NOx rate. Environ. Earth Sci. 2018, 77, 327. [CrossRef]

3. Braun, F.; Orlowsky, J. Non-destructive detection of the efficiency of long-term weathered hydrophobic natural stones using single-sided NMR. J. Cult. Herit. 2020, 41, 51-60. [CrossRef] 
4. Benavente, D.; Martínez-Verdú, F.; Bernabeu, A.; Viqueira, V.; Fort, R.; García del Cura, M.A.; Illucea, C.; Ordóñez, S. Influence of surface roughness on color changes in building stones. Color Res. Appl. 2003, 28, 343-351. [CrossRef]

5. Gorbushina, A.A. Life on the rocks. Environ. Microbiol. 2007, 9, 1613-1631. [CrossRef] [PubMed]

6. Grossi, C.M.; Brimblecombe, P.; Esbert, R.M.; Alonso, F.J. Color changes in architectural limestones from pollution and cleaning. Color Res. Appl. 2007, 32, 320-331. [CrossRef]

7. Polo, A.; Gulotta, D.; Santo, N.; Di Benedetto, C.; Fascio, U.; Toniolo, L.; Villa, F.; Cappitelli, F. Importance of subaerial biofilms and airborne microflora in the deterioration of stonework: A molecular study. Biofouling 2012, 28, 1093-1106. [CrossRef] [PubMed]

8. Adamson, C.; McCabe, S.; Warke, P.A.; McAllister, D.; Smith, B.J. The influence of aspect on the biological colonization of stone in Northern Ireland. Int. Biodeterior. Biodegrad. 2013, 84, 357-366. [CrossRef]

9. Smith, B.J.; McCabe, S.; McAllister, D.; Adamson, C.; Viles, H.; Curran, J.M. A commentary on climate change, stone decay dynamics and the 'greening' of natural stone buildings: New perspectives on 'deep wetting'. Environ. Earth Sci. 2010, 63, 1691-1700. [CrossRef]

10. Mottershead, D.; Lucas, G. The Role of Lichens in Inhibiting Erosion of a Soluble Rock. Lichenologist 2000, 32, 601-609. [CrossRef]

11. Barreiro, P.; Andreotti, A.; Colombini, M.; González, P.; Pozo-Antonio, J.S. Influence of the Laser Wavelength on Harmful Effects on Granite Due to Biofilm Removal. Coatings 2020, 10, 196. [CrossRef]

12. Kessler, D.W.; Anderson, R.E. Stone Exposure Test Wall; Building Materials and Structures Report 125; United States Department of Commerce, National Bureau of Standards: Washington, DC, USA, 1951.

13. Luckat, S. Die Einwirkungen von Luftverunreinigung auf die Bausubstanz des Kölner Doms IV. Kölner Domblatt Köln 1977, 42, 151-181.

14. Zappia, G.; Sabbioni, C.; Riontino, C.; Gobbi, G.; Favoni, O.; Cristina, S. Exposure tests of building materials in urban atmosphere. Sci. Total Environ. 1998, 224, 235-244. [CrossRef]

15. Daly, C. Preliminary results from a legacy indicator tool for measuring climate change related impacts on built heritage. Heritage Sci. 2019, 7, 32. [CrossRef]

16. Comite, V.; De Buergo, M.Á.; Barca, D.; Belfiore, C.; Bonazza, A.; La Russa, M.F.; Pezzino, A.; Randazzo, L.; Ruffolo, S. Damage monitoring on carbonate stones: Field exposure tests contributing to pollution impact evaluation in two Italian sites. Constr. Build. Mater. 2017, 152, 907-922. [CrossRef]

17. Brüggerhoff, S.; Wagener-Lohse, C. Gesteinsverwitterung in Freilandversuchsfeldern-Erfahrungen mit ihrer Errichtung und Nutzung. Bautenschutz + Bausanierung 1989, 12, 76-80.

18. Mirwald, P.W. Umweltbedingte Gesteinszerstörung untersucht mittels Freilandverwitterungsexperimenten. In Sonderheft Bausubstanzerhaltung in der Denkmalpflege. Bautenschutz + Bausanierung; Verlagsges: Oldenburg, Germany, 1986; pp. 24-27.

19. Orlowsky, J.; Braun, F.; Groh, M. The Influence of 30 Years Outdoor Weathering on the Durability of Hydrophobic Agents Applied on Obernkirchener Sandstones. Buildings 2020, 10, 18. [CrossRef]

20. Braun, F.; Orlowsky, J. Zustandsbewertung Hydrophobierter Natursteine. In Erhaltung von Bauwerken: 6. Kolloquium der Technischen Akademie Esslingen, 22. und 23.; Januar, M., Raupach, H., Eds.; Esslinger Verlag J. F. Schreiber Gmbh: Esslingen, Germany, 2019; pp. 243-250.

21. Grimm, W.-D. Bildatlas Wichtiger Denkmalgesteine der Bundesrepublik Deutschland, Teil II Bildband, 2; Erweiterte Auflage, Ebner Verlag: Ulm, Germany, 2018; ISBN 978-3-87188-247-0.

22. DIN 66133:1993-06-Determination of Pore Volume Distribution and Specific Surface Area of Solids by Mercury Intrusion; DIN German Institute for Standardization: Berlin, Germany, 1993.

23. Nijland, T.G.; Dubelaar, C.W.; Van Hees, R.P.; Linden, T.J.M. Black weathering of Bentheim and Obernkirchen sandstone. Heron 2003, 48, 179-195.

24. DIN EN 16581:2015-03-Conservation of Cultural Heritage-Surface Protection for Porous Inorganic Materials -Laboratory Test Methods for The Evaluation of The Performance of Water Repellent Products; DIN German Institute for Standardization: Berlin, Germany, 2014.

25. DIN EN 15886:2010-12—Conservation of Cultural Property-Test Methods-Colour Measurement of Surfaces; DIN German Institute for Standardization: Berlin, Germany, 2010.

26. Malaga, K.; Mueller, U. Validation and Improvement of Procedures for Performance Testing of Anti-Graffiti Agents on Concrete Surfaces. In Proceedings of the Sixth International Conference Concrete under Severe Conditions Environment \& Loading-CONSEC10, Yucatan, Mexico, 7-9 June 2010; pp. 709-716. 
27. García, O.; Malaga, K. Definition of the procedure to determine the suitability and durability of an anti-graffiti product for application on cultural heritage porous materials. J. Cult. Heritage 2012, 13, 77-82. [CrossRef]

28. WTA Merkblatt 3-17: Hydrophobierende Imprägnierung von mineralischen Baustoffen. WTA Merkblatt 3-17-10/D:2010-06; Fraunhofer IRB Verlag: Stuttgart, Germany, 2010.

(C) 2020 by the authors. Licensee MDPI, Basel, Switzerland. This article is an open access article distributed under the terms and conditions of the Creative Commons Attribution (CC BY) license (http://creativecommons.org/licenses/by/4.0/). 